This is an accepted manuscript of an article published by Taylor \& Francis in Journal of Addictive Diseases, 34 (1), 63-74 on 16 Mar 2015, available online:

https://doi.org/10.1080/10550887.2014.975613

\title{
Differential profile and treatment development of drug-addicted patients depending on violent behaviours and/or criminal acts
}

Short title: Drug-addiction, violence and crime

José J. López-Goñi*, Javier Fernández-Montalvo*, Alfonso Arteaga* and Raúl Cacho*

* Departamento de Psicología y Pedagogía. Universidad Pública de Navarra

Campus de Arrosadía s/n

31006 Pamplona (Spain)

Corresponding author:

José J. López-Goñi

Departamento de Psicología y Pedagogía

Universidad Pública de Navarra

Campus de Arrosadía s/n

31006 Pamplona (Spain)

E-mail: josejavier.lopez@unavarra.es

\section{Conflicts of interest}

Dr. López-Goñi reports grants (Res. 359/2012) from the Health Department of Navarre

Government (Spain) during the conduct of the study; José J. López-Goñi, Javier Fernández-Montalvo, Alfonso Arteaga and Raúl Cacho do not have any financial interests that may be interpreted as influencing the research.

\section{Acknowledgments}

The authors thank the "Proyecto Hombre de Navarra" program staff for their help in assessing the clinical sample. 


\begin{abstract}
This study explored the prevalence of violent and/or criminal behaviours in drugaddicted patients. A sample of 252 drug-addicted patients who sought treatment was assessed. Information on violent behaviours, criminal acts, socio-demographic factors, consumption factors, psychopathological factors and personality variables was collected. The sample was divided into four groups according to the presence of violence and/or criminal behaviours. There were significant differences between the groups on some variables. In general, patients associated with both violence and criminal behaviours showed a greater severity in drug consumption and maladjustment variables, as well as a higher rate of treatment dropout and re-entry.
\end{abstract}

Keywords: drug addiction; violent behaviour; crime; comorbidity; dropout. 


\section{Introduction}

The number of studies on the relationship between drug addiction and the development of violent behaviour and criminal acts has increased in recent years. From the point of view of violence, several studies have confirmed a strong relationship between the perpetration of violence and drug addiction ${ }^{1-4}$. Although the causal direction of this relationship has not been identified ${ }^{3,5-8}$, all of these studies showed that drug-addicted patients associated with violent behaviours presented with a higher severity of drug addiction as well as a higher level of consumption and a greater number of associated psychopathological symptoms and maladjustment variables ${ }^{9,10}$.

Regarding criminal conduct, the relationship between commission of criminal acts and addiction is also well established ${ }^{11-17}$. A number of studies have found that amongst prisoners worldwide, $18-30 \%$ of men and $10-24 \%$ of women suffer from alcohol abuse or dependence, and $10-48 \%$ of men and $30-60 \%$ of women abuse or are dependent on other drugs ${ }^{18}$. However, as is the case with violence, the causal direction of this relationship has not been established ${ }^{5,19}$.

In previous studies carried out in Spain by our research team, the differential profile of drug-addicted patients with and without violent behaviours ${ }^{9}$ and drugaddicted patients with and without criminal acts ${ }^{14}$ has been analysed. These studies showed the presence of a differential profile between the samples examined. Generally, drug-addicted patients associated with perpetration of violence showed a higher level of severity in their addiction with regards to consumption, psychopathological symptoms and maladjustment variables. Similar results have been found in comparisons based on criminal behaviour. Moreover, both phenomena are closely related. In both clinical and research settings with drug addicts, it is very common to find patients who show violent and criminal behaviours simultaneously. Other patients may show only one of these 
problems (either violence or crime). Other patients may show neither of these problems; their problem only involves their drug consumption.

From a psychological treatment perspective, it is very relevant to ascertain the different and specific characteristics of these types of patients according to the presence of violence and/or crime and how it pertains to their relationship with treatment development. This knowledge will allow therapists to adapt standard treatments for addiction to more relevant aspects that characterise the patient. Consequently, the present study examined the prevalence rate of violent behaviours and criminal acts (both separately and jointly) in a sample of drug-addicted patients. The main purposes of this study were as follows: a) to assess the specific characteristics of each group of drugaddicted patients (patients associated with violence, criminal acts, or both problems jointly); b) to identify different profiles for each group of patients; c) to determine the relationship between violence and criminal problems with treatment retention and dropout; and d) to establish the rate of subsequent re-entries (during a period of 3 years) in the treatment program according to the presence of violence and/or criminal problems. The main hypothesis of this study is that those patients associated with both violence and crime will present with a more severe profile of addiction and have higher rates of treatment dropout and re-entry.

\section{Method}

The protocol for this study was approved by the ethics committees of the Public University of Navarra and Fundación Proyecto Hombre de Navarra.

\section{Participants}

The initial sample consisted of 284 consecutive drug-addicted patients who presented to the Proyecto Hombre Addiction Treatment Program in Pamplona, Spain to obtain outpatient treatment between October 2008 and July 2010. This program is a 
cognitive-behavioural intervention that is performed on an outpatient basis and is aimed at total abstinence from alcohol and/or other drugs (tobacco is not included). Patients are not required to pay for this treatment program. The therapeutic techniques utilised in the program are related to stimulus control and in vivo exposure as well as relapse prevention. During the first 6 months the treatment includes weekly sessions (45-60 minutes); during the last 6 months sessions are biweekly. Successful program completion typically requires approximately 12 months and is achieved when a patient completes all therapeutic sessions. This program has been shown to be effective for the treatment of addiction ${ }^{20}$.

This study's admission criteria were that the patients had to a) meet the diagnostic criteria for substance dependence according to the $D S M-I V-T R^{21}$; b) be between 18 and 65 years old; c) give their informed consent to participate in the study; and d) complete three assessment sessions. According to these criteria, 252 patients agreed to participate in the study (88.7\% of the initial sample). The remaining patients (32 in total) did not meet the admission criteria for the study, mainly because they did not complete the three assessment sessions $(\mathrm{n}=25)$.

The mean age of the individuals included in the study was 37.6 years $(S D=9.5)$; the sample included 203 (80.6\%) men and 49 (19.4\%) women. The socioeconomic level represented was middle to lower-middle class, as usual in treatment public services in Spain. The main substances that motivated treatment were cocaine $(49.6 \%$ of the sample) and alcohol (43.3\% of the sample) followed by other substances (e.g., heroin, cannabis or amphetamine) in smaller amounts (7.1\% of the sample).

\section{Assessment measures}

The EuropAsi ${ }^{22}$ is the European version of the Addiction Severity Index ${ }^{23}$. This measure, which has an interview format, yields two types of scores: the Interviewer 
Severity Ratings (ISRs) and Composite Scores (CS). The ISRs assess the need for treatment in the following seven areas: a) general medical state, b) labour and economic situation, c) drug consumption, d) alcohol consumption, e) legal problems, f) family and social relationships, and g) psychiatric state. Severity scores range from 0 (no problem) to 9 (extreme problem) in each area, and the cut-off score for each area is 4 . These areas are directly related to the severity of consumption ${ }^{24}$. In this study, we also used the CS on the EuropASI. The CS were developed for research purposes; they are arithmetically based indicators of current (30 days prior) problem severity that range from 0.00 to 1.00, with higher values denoting higher degrees of severity. They assess the following nine areas: a) general medical state, b) economic situation, c) labour satisfaction, d) alcohol consumption, e) drug consumption, f) legal problems, g) family relationships, h) social relationships, and i) psychiatric state. For the current study, the CS were calculated according to the method proposed by Koeter and Hartgers ${ }^{25}$. The Spanish version of the EuropAsi was developed by Bobes, González, Sáiz and Bousoño ${ }^{26}$. In this study, both the ISR and CS were used because they offer complementary information ${ }^{27}$. The short-term test-retest reliabilities of the ASI severity ratings have been reported to be greater than or equal to 0.92 on all domains.

The Symptom Checklist-90-Revised (SCL-90-R) ${ }^{28}$ is a self-administered general psychopathological assessment questionnaire. It consists of 90 questions that are answered on a 5-point Likert-type scale, ranging from 0 (none) to 4 (very much). The questionnaire aims to assess the respondent's psychiatric symptoms. The SCL-90-R has been shown to be sensitive to therapeutic changes and therefore may be used for either single or repeated assessments. The SCL-90-R measures nine areas of primary symptoms: somatisation, obsession-compulsion, interpersonal sensitivity, depression, anxiety, hostility, phobic anxiety, paranoid ideation and psychoticism. It also provides 
three indices that reflect the subject's overall level of symptom severity. The internal consistency of these measures ranges from .70 to .90 .

The Millon Clinical Multiaxial Inventory (MCMI-II) ${ }^{29}$; Spanish version of Millon and Avila ${ }^{30}$ is a self-report questionnaire with 175 true/false items. It was designed to identify clinical states and personality disorders that are similar to those referenced in the DSM-IV-TR. The MCMI-II contains ten basic personality scales: 1) Schizoid, 2) Phobic, 3) Dependent, 4) Histrionic, 5) Narcissistic, 6) Antisocial, 7) Aggressive/sadistic, 8) Compulsive, 9) Passive-aggressive, and 10) Self-destructive. In addition to the basic personality scales, there are three pathological personality scales: Schizotypal (S), Borderline (B) and Paranoid (P). The internal consistency of this measure ranges from .66 to .89.

\section{Procedure}

Once the clinical sample was selected using the criteria previously described, the assessment of the sample was carried out in three sessions before beginning treatment. Each session took place once a week for three weeks; the time interval between sessions was the same for each participant. In the first session, data related to socio-demographic characteristics and drug consumption were collected using the EuropAsi. In the second session, the presence of psychopathological symptoms was assessed using the SCL-90$R$. Finally, in the third session, the prevalence of personality disorders was assessed using the MCMI-II. Moreover, in order to establish the 4 groups studied in this research, information related to the presence of violence problems and/or criminal behaviours was collected from both the clinical record of each patient and some specific items of three areas assessed by the EuropASI: legal problems, family and social relationships, and psychiatric state. 
In this study, patients who reported that they could not control violent impulses in different settings whether with family, friends, or drug abuse partners, as well as those who had committed aggressions to others were considered as violent. On the other hand, patients who had been charged with a crime were considered as patients with associated criminal behavior. Patients who met criteria for both conditions (including the case of a unique violent fact with criminal consequences) were considered as patients with associated both violence and criminal behaviors.

After the three assessment sessions, patients began the standard treatment for addiction performed at Proyecto Hombre. Outpatient treatment at this program consists of a cognitive-behavioural intervention aimed at abstinence from all substances. The treatment lasts an average of 9 months with a subsequent follow-up period of 12 months. Detailed tracking of each patient's progress was maintained to assess whether the subject completed the treatment by obtaining a therapeutic discharge or whether the subject dropped out of the treatment before the conclusion of the program (i.e., abandoned the treatment before obtaining a therapeutic discharge). Moreover, all of the patients in the sample were tracked for a period of 3 years for the purpose of assessing the number of subsequent re-entries into the addiction treatment program.

\section{Data analysis}

Descriptive analyses were conducted for all variables. Comparisons between the groups were carried out using $\chi^{2}$ or ANOVA statistics depending on the nature of the variables studied. A difference of $p<.05$ was considered significant. Statistical analyses were carried out using SPSS (version 15.0 for Windows).

\section{Results}

\section{Prevalence of violence and /or crime}


The rates of violence and/or criminal behavior found after the assessment sessions were the following: 35 patients (13.9\%) were associated with violence; 85 patients (33.7\%) were associated with criminal acts; and 65 patients (25.8\%) were associated with both violence and criminal behaviours. The rest of the sample $(n=67$; 26.8\%) were patients without violence or crime.

\section{Comparison of socio-demographic and consumption variables between groups}

Regarding the socio-demographic variables that were assessed, there were several statistically significant differences between the groups. On average, patients without violence or crime were older than the other groups. On the contrary, the group of patients with both violence and crime was younger than all of the other groups (Table $1)$.

\section{PLACE TABLE 1 HERE}

Although all of the groups had a higher proportion of men than women, the two groups associated with crime were mostly composed of men. Moreover, patients with both violence and crime showed a lower level of education.

The drug-addicted patients with both violence and crime problems were also more likely to have experienced an overdose. Overall, $11.5 \%$ of the total sample experienced a drug overdose during the study period. However, drug-addicted patients

with both violence and crime problems experienced an overdose significantly more often (23.1\% of the sample). This same group also had the highest number of prior treatments for addiction (2.2 prior treatments).

On the other hand, patients with associated crime problems (the group with crime only and the group with both violence and crime) had been consuming cocaine for a longer duration compared with patients without violence or crime problems. However, the group of patients without violence or crime problems had been using 
alcohol for an average of 19.4 years. Regardless, patients with violence and/or crime problems had begun to consume alcohol (over the threshold for abuse) and cocaine at an earlier age.

\section{Comparison of drug addiction severity variables and the results of treatment between groups}

On the EuropAsi, patients with both violent and criminal behaviours had significantly higher scores on almost all of the variables studied (Table 2). In fact, the mean scores for this group showed a significantly greater need for treatment to resolve their problems in 12 out of the 16 areas studied.

\section{PLACE TABLE 2 HERE}

Variables related to the results of the treatment (e.g., dropouts and re-entries) did not show significant differences between the four groups. However, the group with both violence and crime presented with the highest rates of both treatment dropout and re-entry. In fact, when bivariate comparisons were carried out, this group had a statistically significant higher rate of dropout than the group with only violence $\left(X^{2}=4.00 ; p=.043\right)$.

\section{Comparison of psychopathological variables between groups}

Regarding psychopathological variables, the results of the $S C L-90-R$ symptoms inventory showed only a moderate level of psychopathological symptoms in the subjects studied (Table 3). In fact, overall their score was positive in 37 of the 90 items contained in the inventory $($ Positive Symptom Total $=37.4$ ). Furthermore, according to the Global Symptoms Index (GSI) $(X=31.9)$, symptoms did not appear in this sample with any great degree of intensity, as the cut-off point was not exceeded in any of the overall indices or specific dimensions.

PLACE TABLE 3 HERE 
In terms of differentiating between the four subgroups on the areas assessed by the $S C L-90-R$, significant differences were found on seven inventory dimensions. Although none of the subgroups exceeded the cut-off point for any of these dimensions, the patients with both violence and criminal problems presented with significantly more symptoms, mainly when compared with the group without violence or crime.

\section{Comparison of personality variables between groups}

Drug-addicted patients who were associated with both violence and criminal problems showed a higher score on six scales of the MCMI-II related to clusters B and C personality disorders. On the contrary, patients without violence or crime showed a higher score on four scales of the MCMI-II related to cluster A personality disorders (Table 3).

\section{Comparison of maladjustment variables between groups}

Comparisons of some of the maladjustment variables are shown in Table 4. We observed that the patients with violence problems (both with and without criminal problems) showed more adjustment difficulties in family (especially with their father, brothers and sisters), social (friends and colleagues) and labour domains (illegal income sources). Moreover, they had significantly higher rates of parental antecedents of consumption and/or psychiatric problems.

\section{PLACE TABLE 4 HERE}

However, the two groups associated with violence presented with significantly higher rates of victimisation (i.e., being victims of psychological, physical or sexual abuse) and significantly higher scores on variables related to psychiatric maladjustment (mainly in anxiety problems), cognitive problems, hallucinations and suicidal ideations.

\section{Discussion}


In this study, we assessed the prevalence rates of perpetration of violent behaviours and criminal acts in drug-addicted patients in treatment. The results showed a high prevalence of these types of problems in the sample, with $73.4 \%$ of the subjects reporting violence and/or crime problems. These results support data obtained in previous studies with drug addicts in clinical settings when both violence ${ }^{1-4,9}$ and criminal behaviours ${ }^{11-18}$ have been studied. Beyond these prevalence rates, a specific contribution of this study was the analysis of violence and crime both separately and jointly. This constitutes a very relevant field of study because both phenomena are closely related in clinical practice. According to the results obtained in this study, there are different profiles of patients depending on the presence or absence of these types of problems. Nevertheless, the joint study of violence and crime and their influence in treatment outcomes has hardly been studied to date.

Regarding our results concerning the differential profile, patients with both violence and criminal behaviours presented with a more severe profile of addiction. Overall, this group of patients showed higher scores on addiction severity and psychopathological symptom and maladjustment problem measures. However, the group of patients without violence or crime tended to show a better level of adjustment on most of the variables studied. These data support the relevance of violence and crime in drug-addicted patients who seek treatment; therefore, there is a need to develop accurate assessments of the specific impact of violence and crime on the severity of addiction. In this manner, future studies that examine the causal direction of the relationship between crime, violence and addiction are necessary in ways previously proposed by different authors 3 5-8, 11, 19 .

Results related to the impact of violence and crime can be utilised in the development of new and relevant research lines. Patients with both violence and crime 
presented with the highest dropout rate, although they were not found to be significantly different from the other study groups. However, when bivariate analyses were carried out, this group of patients (with both violence and crime) showed a significantly higher rate of dropout compared with patients with only violence, who were the patients with the lowest dropout rate. This is an unexpected and surprising result that needs to be replicated in future studies. Nevertheless, problems related to violence and crime appear to influence treatment development and outcomes. As a consequence, more studies are needed concerning this relationship. A similar pattern occurs with the relationship between violence, crime and the number of re-entries in the treatment program. Although there are no statistically significant differences between the study groups, the highest rate of re-entries is found in patients with both violence and crime.

The present study has a number of limitations. First, because of the exploratory and descriptive nature of this study, the specific causal role that substances play in the development of criminal behaviours and violence cannot be established. Moreover, it is not possible to determine the potential influence of drug use in apprehension. The higher perceived rates of drug use with deviant behavior could simply reflect the fact that cognitive and motor activities necessary for escape, avoiding detection, are all impaired making apprehension more likely. Second, the assessment of the sample was carried out in three sessions, each of which took place once per week. As a result, the final sample may be biased because all of the patients had to attend three consecutive measurements during a three-week period. The patients who dropped out before all of the measurements were completed were not included in this study. This methodological problem might influence the findings and must be considered in further research. Third, data obtained during the follow-up period (dropouts and re-entries) were obtained from institutional sources. It would be interesting to interview patients face-to-face to obtain 
direct information about the influence of violence and crime in their treatment outcomes.

The results of this study support the notion that drug-addicted patients are closely related to violence and crime. Moreover, these two problems interfere with the course of the therapeutic intervention of drug-addicted patients and influence the treatment outcome. Therefore, it is necessary to continue studying the relationship between addiction, violence and crime. 


\section{References}

1. Clements K, Schumacher JA. Perceptual biases in social cognition as potential moderators of the relationship between alcohol and intimate partner violence: A review. Aggression and Violent Behavior 2010; 15:357-368.

2. Fernández-Montalvo J, López-Goñi JJ, Arteaga A. Tratamiento de agresores contra la pareja en programas de atención a drogodependientes: un reto de futuro. Adicciones 2011; 23:5-9.

3. Marshall BDL, Fairbairn N, Li K, Wood E, Kerr T. Physical violence among a prospective cohort of injection drug users: A gender-focused approach. Drug and Alcohol Dependence 2008; 97:237-246.

4. Moore TM, Stuart GL, Meehan JC, Rhatigan DL, Hellmuth JC, Keen SM. Drug abuse and aggression between intimate partners: A meta-analytic review. Clinical Psychology Review 2008; 28:247-274.

5. Boles SM, Miotto K. Substance abuse and violence - A review of the literature. Aggression and Violent Behavior 2003; 8:155-174.

6. Goldstein P. The drugs/violence nexus: A tripartite conceptual framework. Journal of Drug Issues 1985; 15:493-506.

7. Goldstein P. Drugs and violent crime. In: Weiner NA, Wolfgana ME Eds. Pathways to criminal violence. Beverly Hills: SAGE, 1989:16-48.

8. Martin SE, Bryant K. Gender differences in the association of alcohol intoxication and illicit drug abuse among persons arrested for violent and property offenses. Journal of Substance Abuse 2001; 13:563-581. 
9. Fernández-Montalvo J, López-Goñi JJ, Arteaga A. Violent behaviours in drug addiction: Differential profiles of drug-addicted patients with and without violence problems. Journal of Interpersonal Violence 2012; 27:142-157.

10. Landa N, Fernandez-Montalvo J, López-Goñi JJ, Lorea I. Comorbilidad psicopatológica en el alcoholismo: Un estudio descriptivo. International Journal of Clinical and Health Psychology 2006; 6:253-269.

11. Bennett T, Holloway K. The association between multiple drug misuse and crime. International Journal of Offender Therapy and Comparative Criminology 2005; 49:63-81.

12. Coid J, Carvell A, Kittler Z, Healey A, Henderson J. Opiates, criminal behaviour, and methadone treatment. London: Home Office, 2000.

13. Felson RB, Staff J. The effects of alcohol intoxication on violent versus other offending. Criminal Justice and Behavior 2010; 37:1343-1360.

14. Fernandez-Montalvo J, Lopez-Goni JJ, Arteaga A, Cacho R. Criminological profile of patients in addiction treatment. Adicciones 2013; 25:146-155.

15. Menard SW, Mihalic SF, Huizinga D. Drugs and crime revisited. Academy of Criminal Justice Science 2001; 18:269-299.

16. Sanford JS, Arrigo BA. Lifting the cover on drug courts: Evaluation findings and policy concerns. International Journal of Offender Therapy and Comparative Criminology 2005; 49:239-259.

17. Santamaría JJ, Chait L. Drogadicción y delincuencia. Perspectiva desde una prisión. Adicciones 2004; 16:207-217.

18. Fazel S, Bains P, Doll H. Substance abuse and dependence in prisoners: a systematic review. Addiction 2006; 101:181-191. 
19. Kuhns JB, Clodfelter TA. Illicit drug-related psychopharmacological violence: The current understanding within a causal context. Aggression and Violent Behavior 2009; 14:69-78.

20. Fernandez-Montalvo J, Lopez-Goni JJ, Illescas C, Landa N, Lorea I. Evaluation of a Therapeutic Community Treatment Program: A Long-Term Follow-up Study in Spain. Subst Use Misuse 2008; 43:1362-77.

21. American Psychiatric Association. Diagnostic and statistical manual of mental disorders (4th Ed. Rev.). Washington, D.C.: APA, 2000.

22. Kokkevi A, Hartgers C. European adaptation of a multidimensional assessment instrument for drug and alcohol dependence. European Addiction Research 1995; $1: 208-210$.

23. McLellan AT, Luborsky L, Woody GE, O’Brien CP. An improved diagnostic evaluation instrument for substance abuse patients: The Addiction Severity Index. The Journal of Nervous and Mental Disease 1980:26-33.

24. López-Goñi JJ, Fernández-Montalvo J, Menéndez JC, Yudego F, García AR, Esarte S. Group and individual change in the treatment of drug addictions: A follow-up study in therapeutic communities. Spanish Journal of Psychology 2010; 13:906-913. 25. Koeter MWJ, Hartgers C. European addiction severity index europasi. Cost a6. Preliminary procedure for the computation of the europasi composite scores: The Amsterdam Institute for Addiction Research, 1997.

26. Bobes J, González MP, Sáiz PA, Bousoño M. Índice europeo de severidad de la adicción: EuropASI. Versión española. Paper presented at Actas de la IV Reunión Interregional de Psiquiatría, 1996. 
27. López-Goñi JJ, Fernández-Montalvo J, Arteaga A. Predictive validity of the EuropAsi: Clinical diagnosis or composite scoring? Journal of Substance Abuse Treatment 2012; 42:392-399.

28. González de Rivera JL. Versión española del SCL-90-R. Madrid: TEA, 2002.

29. Millon T. Millon Clinical Multiaxial Inventory- II (MCMI II). Minneapolis:

National Computer Systems, 1997.

30. Millon T, Ávila A. Inventario Clínico Multiaxial de Millon (MCMI-II). Madrid: TEA Ediciones, 1998. 
Table 1. Comparisons of socio-demographic and drug addiction characteristics

\begin{tabular}{|c|c|c|c|c|c|c|c|c|c|c|c|c|}
\hline & \multicolumn{2}{|c|}{$\begin{array}{c}\text { All } \\
\mathrm{N}=252\end{array}$} & \multicolumn{2}{|c|}{$\begin{array}{c}\text { Without Violence } \\
\text { or Crime } \\
\text { (a) } \\
(\mathbf{n}=67)\end{array}$} & \multicolumn{2}{|c|}{$\begin{array}{c}\text { With } \\
\text { Violence } \\
(\mathbf{b}) \\
(\mathbf{n}=35)\end{array}$} & \multicolumn{2}{|c|}{$\begin{array}{c}\text { With } \\
\text { Crime } \\
(\mathbf{c}) \\
(\mathbf{n}=85)\end{array}$} & \multicolumn{2}{|c|}{$\begin{array}{c}\text { With Violence } \\
\text { and Crime } \\
(d) \\
(\mathbf{n}=65)\end{array}$} & \multirow[b]{2}{*}{$\boldsymbol{F}$} & \multirow[b]{3}{*}{$\mathrm{a}>\mathrm{b}^{*}, \mathrm{~d}^{* *} ; \mathrm{c}>\mathrm{d}^{*}$} \\
\hline & $M$ & $(\mathrm{SD})$ & $M$ & (SD) & $M$ & (SD) & $M$ & (SD) & $M$ & (SD) & & \\
\hline \multirow[t]{2}{*}{ Mean age } & 37.6 & $(9.5)$ & 40.3 & $(9.6)$ & 36.0 & $(9.3)$ & 38.0 & $(10.2)$ & 35.0 & $(7.5)$ & $4.1^{* *}$ & \\
\hline & $\mathbf{N}$ & (\%) & $\mathbf{n}$ & (\%) & $\mathbf{n}$ & (\%) & $\mathbf{n}$ & (\%) & $\mathbf{n}$ & (\%) & & $X^{2}(d f)$ \\
\hline \multicolumn{13}{|l|}{ Sex } \\
\hline Men & 203 & $(80.6 \%)$ & 46 & $(68.7 \%)$ & 22 & $(62.9 \%)$ & 77 & (90.6\%) & 58 & $(89.2 \%)$ & \multirow{2}{*}{\multicolumn{2}{|c|}{$21.6(3)^{* * *}$}} \\
\hline Women & 49 & (19.4\%) & 21 & $(31.3 \%)$ & 13 & (37.1\%) & 8 & $(9.4 \%)$ & 7 & $(10.8 \%)$ & & \\
\hline \multicolumn{13}{|l|}{ Marital Status } \\
\hline Single & 122 & $(48.4 \%)$ & 22 & $(32.8 \%)$ & 17 & $(48.6 \%)$ & 44 & (51.8\%) & 39 & $(60.0 \%)$ & \multirow{3}{*}{\multicolumn{2}{|c|}{$12.1(6)$}} \\
\hline Married & 76 & $(30.2 \%)$ & 25 & $(37.3 \%)$ & 13 & $(37.1 \%)$ & 23 & $(27.1 \%)$ & 15 & $(23.1 \%)$ & & \\
\hline Divorced & 54 & $(21.4 \%)$ & 20 & $(29.9 \%)$ & 5 & $(14.3 \%)$ & 18 & $(21.2 \%)$ & 11 & $(16.9 \%)$ & & \\
\hline \multicolumn{13}{|l|}{ Education } \\
\hline None & 28 & $(11.2 \%)$ & 5 & $(7.5 \%)$ & 1 & $(2.9 \%)$ & 7 & $(8.3 \%)$ & 15 & $(23.1 \%)$ & \multirow{4}{*}{\multicolumn{2}{|c|}{$27.7(9)^{* *}$}} \\
\hline Primary school & 135 & $(53.8 \%)$ & 32 & $(47.8 \%)$ & 17 & $(48.6 \%)$ & 50 & (59.5\%) & 36 & $(55.4 \%)$ & & \\
\hline Secondary school & 62 & $(24.7 \%)$ & 16 & $(23.9 \%)$ & 13 & $(37.1 \%)$ & 21 & $(25.0 \%)$ & 12 & $(18.5 \%)$ & & \\
\hline University & 26 & $(10.4 \%)$ & 14 & $(20.9 \%)$ & 4 & $(11.4 \%)$ & 6 & $(7.1 \%)$ & 2 & $(3.1 \%)$ & & \\
\hline \multicolumn{13}{|l|}{ Employment situation } \\
\hline Employed & 166 & $(65.9 \%)$ & 44 & $(65.7 \%)$ & 27 & $(77.1 \%)$ & 58 & $(68.2 \%)$ & 37 & $(56.9 \%)$ & \multirow{3}{*}{\multicolumn{2}{|c|}{$9.6(6)$}} \\
\hline Unemployed & 68 & $(27.0 \%)$ & 15 & $(22.4 \%)$ & 6 & $(17.1 \%)$ & 22 & $(25.9 \%)$ & 25 & $(38.5 \%)$ & & \\
\hline Others (student, retired...) & 18 & $(7.1 \%)$ & 8 & $(11.9 \%)$ & 2 & $(5.7 \%)$ & 5 & $(5.9 \%)$ & 3 & $(4.6 \%)$ & & \\
\hline \multicolumn{13}{|c|}{ Substance that motivated treatment } \\
\hline Alcohol & 109 & $(43.3 \%)$ & 34 & $(50.7 \%)$ & 15 & $(42.9 \%)$ & 32 & $(37.6 \%)$ & 28 & $(43.1 \%)$ & & $4.9(6)$ \\
\hline
\end{tabular}




\begin{tabular}{|c|c|c|c|c|c|c|c|c|c|c|c|c|c|}
\hline Cocaine & & 125 & $(49.6 \%)$ & 30 & $(44.8 \%)$ & 17 & $(48.6 \%)$ & 48 & $(56.5 \%)$ & 30 & $(46.2 \%)$ & & \\
\hline Others (heroin, cannabis...) & & 18 & $(7.1 \%)$ & 3 & $(4.5 \%)$ & 3 & $(8.6 \%)$ & 5 & $(5.9 \%)$ & 7 & $(10.8 \%)$ & & \\
\hline Drug overdose & & 29 & $(11.5 \%)$ & 2 & $(3.0 \%)$ & 5 & $(14.3 \%)$ & 7 & $(8.2 \%)$ & 15 & $(23.1 \%)$ & & $14.5 * *(3)$ \\
\hline \multirow[t]{2}{*}{ Prior treatments for addiction } & & 166 & $(65.9 \%)$ & 43 & $(64.2 \%)$ & 22 & $(62.9 \%)$ & 53 & $(62.4 \%)$ & 48 & $(73.8 \%)$ & & $2.5(3)$ \\
\hline & $N$ & $M$ & $(S D)$ & $M$ & $(S D)$ & $M$ & (SD) & $M$ & $(S D)$ & $M$ & (SD) & $F$ & \\
\hline Prior treatments for addiction & 252 & 1.6 & $(2.4)$ & 1.4 & $(2.1)$ & 1.1 & $(1.3)$ & 1.5 & $(2.6)$ & 2.2 & $(2.9)$ & 1.9 & $d>b^{*}$ \\
\hline \multicolumn{14}{|l|}{ Lifetime use... } \\
\hline Alcohol & 216 & 15.8 & $(10.5)$ & 19.4 & (11.9) & 11.4 & $(7.2)$ & 15.9 & $(11.4)$ & 14.4 & $(8.1)$ & $4.6^{\star \star}$ & $\mathrm{a}>\mathrm{b}^{* *}, \mathrm{~d}^{*} ; \mathrm{c}>\mathrm{b}^{*}$ \\
\hline Alcohol over threshold & 188 & 12.0 & $(10.1)$ & 13.7 & $(11.1)$ & 9.2 & $(7.5)$ & 12.7 & $(11.3)$ & 11.0 & $(8.2)$ & 1.4 & \\
\hline Heroin & 28 & 4.8 & $(4.2)$ & 4.2 & $(2.4)$ & 4.0 & $(3.4)$ & 5.7 & $(4.0)$ & 4.4 & $(5.7)$ & 0.2 & \\
\hline Cocaine & 160 & 5.3 & (4.8) & 3.6 & (3.4) & 4.5 & $(2.9)$ & 5.7 & (5.3) & 6.2 & $(5.5)$ & 2.4 & c, $d>a^{*}$ \\
\hline Stimulants & 90 & 4.9 & $(5.1)$ & 6.2 & $(6.8)$ & 6.0 & $(8.4)$ & 3.5 & $(2.6)$ & 5.2 & (3.8) & 1.3 & \\
\hline Cannabis & 124 & 9.2 & (7.3) & 8.6 & (7.3) & 8.3 & $(6.4)$ & 9.1 & (7.3) & 10.0 & (7.9) & 0.3 & \\
\hline Multiple substances & 69 & 7.3 & $(6.1)$ & 6.1 & $(6.3)$ & 5.8 & $(4.2)$ & 6.8 & $(5.3)$ & 9.2 & $(7.5)$ & 1.1 & \\
\hline \multicolumn{14}{|l|}{ Age at onset } \\
\hline Alcohol & 217 & 17 & $(4.7)$ & 18 & $(5.4)$ & 17 & $(5.5)$ & 18 & $(4.2)$ & 16 & $(4.2)$ & 1.2 & \\
\hline Alcohol over threshold & 189 & 23 & $(7.5)$ & 25 & $(8.2)$ & 24 & $(8.0)$ & 22 & $(7.5)$ & 21 & $(5.9)$ & $3.1^{*}$ & $a>c^{*}, d^{* *}$ \\
\hline Heroin & 28 & 20 & (5.9) & 18 & $(0.5)$ & 21 & $(6.4)$ & 19 & $(7.3)$ & 22 & $(5.7)$ & 0.7 & \\
\hline Cocaine & 161 & 24 & (6.4) & 27 & $(6.4)$ & 22 & $(5.6)$ & 24 & (6.5) & 22 & $(6.2)$ & $4.1^{* *}$ & $\mathrm{a}>\mathrm{b}^{*}, \mathrm{~d}^{* *}$ \\
\hline Stimulants & 90 & 18 & $(4.4)$ & 18 & $(2.5)$ & 18 & (3.6) & 19 & $(5.6)$ & 18 & $(4.2)$ & 0.1 & \\
\hline Cannabis & 126 & 16 & $(3.4)$ & 16 & $(4.6)$ & 16 & $(2.2)$ & 16 & $(2.4)$ & 17 & $(4.2)$ & 0.1 & \\
\hline Multiple substances & 68 & 22 & $(6.4)$ & 25 & $(7.5)$ & 26 & $(7.8)$ & 21 & $(4.9)$ & 20 & $(5.7)$ & $3.0^{*}$ & $a, b>d^{*}$ \\
\hline
\end{tabular}

${ }^{*} p<.05 ;{ }^{* *} p<.01 ; * * * p<.001$

Journal of Addictive Diseases, (2015) 34:63-74, DOI: 10.1080/10550887.2014.975613 
Table 2. Comparisons of drug addiction severity variables and the results of treatment

\begin{tabular}{|c|c|c|c|c|c|c|c|}
\hline & $\begin{array}{c}\text { All } \\
(\mathrm{N}=252)\end{array}$ & $\begin{array}{c}\text { Without } \\
\text { Violence } \\
\text { or Crime } \\
(\mathbf{a}) \\
(\mathrm{n}=67)\end{array}$ & $\begin{array}{c}\text { With } \\
\text { Violence } \\
\text { (b) } \\
(\mathbf{n}=35)\end{array}$ & $\begin{array}{c}\text { With } \\
\text { Crime } \\
\text { (c) } \\
(\mathbf{n}=\mathbf{8 5})\end{array}$ & $\begin{array}{c}\text { With } \\
\text { Violence } \\
\text { and Crime } \\
(d) \\
(n=65)\end{array}$ & & \\
\hline EuropASI ISR Scores & $M(S D)$ & $M(S D)$ & $M(S D)$ & $M(S D)$ & $M(S D)$ & $F$ & \\
\hline Medical & $2.0(1.4)$ & $2.2(1.6)$ & $1.9(1.1)$ & $2.1(1.4)$ & $1.9(1.2)$ & 0.4 & -- \\
\hline Employment/Support & $2.4(1.7)$ & $2.5(1.8)$ & $2.0(1.4)$ & $2.1(1.5)$ & $2.8(1.8)$ & $2.8^{*}$ & $\mathrm{~d}>(\mathrm{b}, \mathrm{c})^{*}$ \\
\hline Alcohol use & $3.9(2.0)$ & $3.9(2.1)$ & $3.8(1.7)$ & $3.6(2.0)$ & $4.3(2.0)$ & 1.4 & $\mathrm{~d}>\mathrm{c}^{*}$ \\
\hline Drug use & $3.4(2.1)$ & $2.7(1.9)$ & $3.4(2.0)$ & $3.4(2.1)$ & $4.1(2.1)$ & $5.1^{* *}$ & $(d, c)>a^{*}$ \\
\hline Legal & $1.8(1.5)$ & $1.0(0.8)$ & $1.1(0.4)$ & $2.0(1.4)$ & $2.6(1.8)$ & $21.8 * * *$ & $d>a^{*}>(b, c)^{*}$ \\
\hline Family/Social & $3.7(1.7)$ & $3.3(1.7)$ & $3.7(1.6)$ & $3.6(1.6)$ & $4.2(1.8)$ & $3.5^{*}$ & $\mathrm{~d}>(\mathrm{a}, \mathrm{c})^{*}$ \\
\hline Psychiatric & $3.2(1.7)$ & $2.9(1.9)$ & $3.4(1.2)$ & $2.9(1.5)$ & $3.9(1.9)$ & $5.9 * *$ & $\mathrm{~d}>(\mathrm{a}, \mathrm{c})^{*}$ \\
\hline EuropASI CS & $M(S D)$ & $M(S D)$ & $M(S D)$ & $M(S D)$ & $M(S D)$ & $F$ & \\
\hline Medical & $.22(.25)$ & $.22(.25)$ & $.23(.25)$ & $.22(.26)$ & $.22(.26)$ & 0.1 & -- \\
\hline Economic situation & $.38(.45)$ & $.45(.46)$ & $.27(.41)$ & $.29(.42)$ & $.49(.48)$ & $3.7^{*}$ & $\mathrm{a}>\mathrm{c}^{*} ; \mathrm{d}>\mathrm{b}^{*}, \mathrm{c}^{* *}$ \\
\hline Labour satisfaction & $.27(.32)$ & $.31(.35)$ & $.27(.29)$ & $.19(.27)$ & $.34(.35)$ & $3.3^{*}$ & $(\mathrm{a}, \mathrm{d})>\mathrm{C}^{*}, * *$ \\
\hline Alcohol & $.31(.24)$ & $.29(.23)$ & $.28(.19)$ & $.33(.24)$ & $.34(.27)$ & 1.0 & -- \\
\hline Drug use & $.13(.12)$ & $.09(.11)$ & $.15(.13)$ & $.14(.12)$ & $.13(.11)$ & $3.1^{*}$ & $(b, d), c>a^{*, * *}$ \\
\hline Legal & $.11(.19)$ & $.11(.20)$ & $.12(.20)$ & $.12(.19)$ & $.14(.24)$ & 0.2 & \\
\hline Family & $.27(.23)$ & $.23(.23)$ & $.28(.23)$ & $.27(.23)$ & $.31(.23)$ & 1.4 & $d>a^{*}$ \\
\hline Others & $.15(.18)$ & $.10(.18)$ & $.18(.19)$ & $.13(.16)$ & $.20(.20)$ & $4.2 * *$ & $\mathrm{~d}>\mathrm{a}^{* *}, \mathrm{c}^{*} ; \mathrm{b}>\mathrm{a}^{*}$ \\
\hline \multirow[t]{2}{*}{ Psychiatric } & $.21(.19)$ & $.22(.19)$ & $.23(.16)$ & $.16(.18)$ & $.26(.20)$ & $3.4^{*}$ & $\mathrm{~d}, \mathrm{a}>\mathrm{c}^{* * ; *}$ \\
\hline & n (\%) & n (\%) & n (\%) & n (\%) & n (\%) & $X^{2}$ & \\
\hline Dropouts & 98 (38.9\%) & $25(37.3 \%)$ & $9(25.7 \%)$ & $34(40.0 \%)$ & $30(46.2 \%)$ & 4.1 & \\
\hline $\begin{array}{l}\text { Re-entries (during the } 3 \\
\text { following years) }\end{array}$ & 33 (13.1\%) & $9(13.4 \%)$ & $4(11.4 \%)$ & $9(10.6 \%)$ & 11 (16.9\%) & 1.40 & \\
\hline
\end{tabular}

$$
{ }^{*} p<.05 ; * * p<.01 ; * * * p<.001
$$


Table 3. Comparisons of clinical variables

\begin{tabular}{|c|c|c|c|c|c|c|c|}
\hline & $\begin{array}{c}\text { All } \\
(\mathrm{N}=252)\end{array}$ & $\begin{array}{c}\text { Without } \\
\text { Violence } \\
\text { or Crime } \\
(\mathbf{a}) \\
(\mathbf{n}=67) \\
\end{array}$ & $\begin{array}{c}\text { With } \\
\text { Violence } \\
(\mathbf{b}) \\
(\mathbf{n}=35)\end{array}$ & $\begin{array}{c}\text { With } \\
\text { Crime } \\
(\mathbf{c}) \\
(\mathbf{n}=85)\end{array}$ & $\begin{array}{c}\text { With } \\
\text { Violence } \\
\text { and Crime } \\
(\mathbf{d}) \\
(\mathbf{n}=65)\end{array}$ & & \\
\hline SCL-90-R & $M(S D)$ & $M(S D)$ & $M(S D)$ & $M(S D)$ & $M(S D)$ & $F$ & \\
\hline GSI & 31.9 (25.9) & $27.9(23.9)$ & $35.1(29.1)$ & $30.3(26.2)$ & $36.5(25.5)$ & 1.5 & -- \\
\hline PSDI & $27.8(23.9)$ & 26.3 (23.9) & $29.4(27.3)$ & $27.6(23.1)$ & $28.7(23.6)$ & 0.2 & -- \\
\hline PST & $37.4(28.5)$ & $32.2(25.9)$ & $39.4(29.6)$ & $35.9(30.2)$ & $43.8(27.6)$ & 2.0 & $d>a^{*}$ \\
\hline Somatisation & $27.3(22.6)$ & $27.5(22.4)$ & $28.4(25.1)$ & $27.8(24.1)$ & $25.9(19.5)$ & 0.1 & -- \\
\hline Obsession-compulsion & $36.6(24.7)$ & $31.1(23.0)$ & $40.4(26.9)$ & $35.6(24.3)$ & 41.7 (24.9) & 2.4 & $d>a^{*}$ \\
\hline Interpersonal sensitivity & $40.1(27.5)$ & $36.8(25.7)$ & $41.0(28.9)$ & $38.1(27.6)$ & $45.8(28.1)$ & 1.4 & $d>c^{*}$ \\
\hline Depression & $32.2(24.9)$ & $29.8(23.1)$ & $33.8(29.5)$ & $29.3(24.7)$ & 37.7 (23.9) & 1.7 & b y d $>a^{* *}$ \\
\hline Anxiety & $28.8(24.7)$ & $26.3(20.9)$ & $32.8(27.9)$ & $26.4(26.0)$ & $32.2(24.7)$ & 1.2 & \\
\hline Hostility & $37.4(26.3)$ & $30.6(23.4)$ & $44.8(28.6)$ & $36.5(25.0)$ & $41.5(28.1)$ & $3.0^{*}$ & b y d $>a^{* *}$ \\
\hline Phobic anxiety & $33.5(25.5)$ & $31.3(23.0)$ & 35.7 (28.9) & $31.5(25.7)$ & $37.2(26.0)$ & 0.9 & \\
\hline Paranoid ideation & $40.8(25.7)$ & $37.6(26.0)$ & $39.7(22.0)$ & $38.9(26.4)$ & $47.0(25.7)$ & 1.8 & $\mathrm{~d}>\mathrm{a}^{*}$ \\
\hline Psychoticism & $39.2(24.8)$ & $35.8(22.3)$ & $43.8(27.4)$ & $35.0(25.9)$ & $45.5(23.0)$ & $3.1^{*}$ & b y d $>a^{* *}$ \\
\hline MCMI-II & $M(S D)$ & $M(S D)$ & $M(S D)$ & $M(S D)$ & $M(S D)$ & $\boldsymbol{F}$ & \\
\hline Schizoid & $58.1(27.8)$ & $58.8(55.6)$ & $55.6(25.0)$ & $59.9(33.8)$ & $56.6(24.4)$ & 0.3 & -- \\
\hline Phobic & $49.3(27.9)$ & $57.2(25.3)$ & $53.5(26.9)$ & $40.7(27.1)$ & $50.3(29.6)$ & 5.0 & $(a, b, d)>c^{*}$ \\
\hline Dependence & $59.9(24.2)$ & $67.7(21.1)$ & $57.3(25.9)$ & $59.2(24.1)$ & $54.1(24.7)$ & 3.9 & $\mathrm{a}>(\mathrm{b}, \mathrm{c})^{*}, \mathrm{~d}^{* *}$ \\
\hline Histrionic & $54.2(20.2)$ & $52.1(19.1)$ & $55.1(20.9)$ & $52.9(20.4)$ & $57.6(20.6)$ & 1.0 & \\
\hline Narcissistic & 50.7 (23.6) & $48.6(22.1)$ & $49.7(23.4)$ & $48.5(25.5)$ & $56.3(22.3)$ & 1.7 & $d>c^{*}$ \\
\hline Antisocial & $53.2(23.4)$ & $47.4(21.7)$ & $54.1(21.9)$ & $49.8(24.1)$ & $63.2(22.3)$ & 6.3 & $d>(a, c) * * *$ \\
\hline Aggressive-sadistic & $52.5(22.7)$ & $48.4(23.5)$ & $56.5(20.7)$ & $47.8(21.4)$ & $60.7(22.4)$ & 5.5 & $\mathrm{~d}>(\mathrm{a}, \mathrm{c})^{* * *}$ \\
\hline Compulsive & $54.2(21.0)$ & $58.4(20.0)$ & $53.7(21.1)$ & 53.9 (21.9) & $50.4(20.6)$ & 1.6 & $\mathrm{a}>\mathrm{d}^{*}$ \\
\hline Passive-aggressive & $45.3(30.5)$ & $41.0(29.9)$ & $52.3(30.9)$ & $36.6(27.8)$ & $57.1(30.5)$ & 7.0 & $\mathrm{~d}>(\mathrm{a}, \mathrm{c})^{* * *}$ \\
\hline Self-destructive & $48.0(24.2)$ & $51.2(22.2)$ & $53.8(26.4)$ & $42.5(23.5)$ & $49.0(25.0)$ & 2.6 & $(a, b)>c^{*}$ \\
\hline Schizotypal & $41.8(23.3)$ & $44.9(19.6)$ & $40.5(20.2)$ & 35.7 (23.9) & $47.2(25.9)$ & 3.7 & $(\mathrm{a}, \mathrm{d})>\mathrm{c}^{*, * *}$ \\
\hline Borderline & 39.5 (25.9) & $37.8(24.7)$ & $42.4(22.2)$ & $34.2(25.7)$ & $46.8(27.8)$ & 3.2 & $d>\left(a^{*}, c^{* *}\right)$ \\
\hline Paranoid & $56.0(16.7)$ & $56.6(16.1)$ & 55.0 (13.9) & $53.8(18.2)$ & $59.0(16.4)$ & 1.3 & -- \\
\hline
\end{tabular}

$$
{ }^{*} p<.05 ; * * p<.01 ; * * * p<.001
$$


Table 4. Comparison of Maladjustment Variables

\begin{tabular}{|c|c|c|c|c|c|c|c|c|}
\hline & & $N$ & $\begin{array}{c}\text { All } \\
(\mathrm{N}=252) \\
N(\%)\end{array}$ & $\begin{array}{l}\text { Without Violence } \\
\text { or Crime } \\
\text { (a) } \\
(\mathbf{n}=67) \\
n(\%)\end{array}$ & $\begin{array}{c}\text { With } \\
\text { Violence } \\
\text { (b) } \\
(\mathbf{n}=35) \\
n(\%)\end{array}$ & $\begin{array}{c}\text { With } \\
\text { Crime } \\
(\mathbf{c}) \\
(\mathbf{n}=85) \\
n(\%)\end{array}$ & $\begin{array}{c}\text { With Violence } \\
\text { and Crime } \\
\text { (d) } \\
(\mathbf{n}=65) \\
n(\%)\end{array}$ & $X^{2}(d f)$ \\
\hline \multicolumn{9}{|l|}{ Family maladjustment } \\
\hline \multirow{5}{*}{ Problems with the patient's } & Mother & 249 & 75 (30.1\%) & $16(24.2 \%)$ & $12(34.3 \%)$ & $21(25.0 \%)$ & 26 (40.6\%) & $5.8(3)$ \\
\hline & Father & 241 & 86 (35.7\%) & $13(20.6 \%)$ & 17 (51.5\%) & $24(29.6 \%)$ & $32(50.0 \%)$ & $16.8^{* *}(3)$ \\
\hline & Brother(s)/sister(s) & 241 & 79 (32.8\%) & $20(30.3 \%)$ & $9(27.3 \%)$ & $20(25.0 \%)$ & $30(48.4 \%)$ & $9.7 *(3)$ \\
\hline & Sexual partner & 239 & 146 (61.1\%) & $35(54.7 \%)$ & $20(58.8 \%)$ & 46 (57.5\%) & $45(73.8 \%)$ & $5.7(3)$ \\
\hline & Son(s)/daughter(s) & 120 & 15 (12.5\%) & $8(18.6 \%)$ & 0 & $4(11.4 \%)$ & $3(10.7 \%)$ & $3.6(3)$ \\
\hline \multicolumn{9}{|l|}{ Social maladjustment } \\
\hline \multirow{3}{*}{ Problems with the patient's } & Close friends & 243 & $63(25.9 \%)$ & $7(10.9 \%)$ & $11(31.4 \%)$ & $21(25.3 \%)$ & $24(39.3 \%)$ & $13.8^{* *}(3)$ \\
\hline & Neighbours & 248 & $31(12.5 \%)$ & $7(10.8 \%)$ & $5(14.3 \%)$ & $7(8.3 \%)$ & $12(18.8 \%)$ & $3.9(3)$ \\
\hline & Work colleagues & 248 & $71(28.6 \%)$ & $10(15.4 \%)$ & $9(25.7 \%)$ & $24(28.6 \%)$ & $28(43.8 \%)$ & $12.9 * *(3)$ \\
\hline \multicolumn{9}{|l|}{ Labour maladjustment } \\
\hline \multirow{4}{*}{ Main income source } & Employment & & $158(62.7 \%)$ & $37(55.2 \%)$ & $26(74.3 \%)$ & $61(71.8 \%)$ & 34 (52.3\%) & \multirow{4}{*}{$18.9 *(9)$} \\
\hline & $\begin{array}{l}\text { Colleagues and/or } \\
\text { relatives }\end{array}$ & 252 & 37 (14.7\%) & $10(14.9 \%)$ & $7(20.0 \%)$ & $8(9.4 \%)$ & 12 (18.5\%) & \\
\hline & Social services & & $42(16.7 \%)$ & $15(22.4 \%)$ & $2(5.7 \%)$ & $14(16.5 \%)$ & $11(16.9 \%)$ & \\
\hline & Illegal & & $15(5.9 \%)$ & $5(7.5 \%)$ & 0 & $2(2.4 \%)$ & $8(12.3 \%)$ & \\
\hline \multicolumn{2}{|c|}{$\begin{array}{l}\text { Parental antecedents of consumption and/or } \\
\text { psychiatric problems }\end{array}$} & 252 & $69(27.4 \%)$ & $14(20.9 \%)$ & $12(34.3 \%)$ & $16(18.8 \%)$ & 27 (41.5\%) & $11.9^{* *}(3)$ \\
\hline \multicolumn{2}{|l|}{ Victim of abuse } & 252 & $115(46.0 \%)$ & $26(39.4 \%)$ & $21(61.8 \%)$ & $29(34.1 \%)$ & $39(60.0 \%)$ & $14.5^{* * *}(3)$ \\
\hline \multicolumn{9}{|l|}{ Psychiatric maladjustment } \\
\hline \multicolumn{2}{|l|}{ Depression problems } & 252 & $131(52.0 \%)$ & $31(46.3 \%)$ & $18(51.4 \%)$ & $43(50.6 \%)$ & $39(60.0 \%)$ & $2.6(3)$ \\
\hline \multicolumn{2}{|l|}{ Anxiety problems } & 252 & $153(60.7 \%)$ & $38(56.7 \%)$ & 27 (77.1\%) & $42(49.4 \%)$ & $46(70.8 \%)$ & $11.7^{* *}(3)$ \\
\hline
\end{tabular}




\begin{tabular}{|c|c|c|c|c|c|c|c|}
\hline Cognitive problems & 252 & 103 (40.9\%) & $22(32.8 \%)$ & 19 (54.3\%) & $26(30.6 \%)$ & $36(55.4 \%)$ & $13.8 * *(3)$ \\
\hline Hallucinations & 252 & 40 (15.9\%) & $5(7.5 \%)$ & $9(25.7 \%)$ & $10(11.8 \%)$ & $16(24.6 \%)$ & $10.9 * *(3)$ \\
\hline Suicidal ideations & 252 & $100(39.7 \%)$ & $16(23.9 \%)$ & $15(42.9 \%)$ & $34(40.0 \%)$ & $35(53.8 \%)$ & $12.6 * *(3)$ \\
\hline Suicide attempt & 249 & 40 (16.1\%) & $9(13.6 \%)$ & $7(20.0 \%)$ & $8(9.4 \%)$ & $16(25.4 \%)$ & $7.6(3)$ \\
\hline
\end{tabular}

${ }^{*} p<.05 ; * * p<.01 ;{ }^{* * *} p<.001$

Journal of Addictive Diseases, (2015) 34:63-74, DOI: 10.1080/10550887.2014.975613 